\title{
An Unusual Case of Foreign Body Aspiration in an Infant
}

\author{
Dias E \\ Department of Pediatrics, K.V.G. Medical College, Mangalore, Karnataka, India
}

\begin{tabular}{l}
\hline Address for correspondence: \\
Dr. Edwin Dias, \\
Professor and Head Pediatrics, Casa \\
Leila. S.L. Mathias Road, Highlands, \\
Mangalore-575 002, \\
Karnataka, India. \\
E-mail: dredwindias@gmail.com \\
\hline
\end{tabular}

\begin{abstract}
Inhalation of foreign body is a serious condition in childhood and may result in acute respiratory distress, lung injury or death. A nine month old baby with history of severe respiratory distress, cyanosis and gasping breathing diagnosed as foreign body aspiration due to a balloon which was recovered post mortem during the removal of the endotracheal tube.
\end{abstract}

Keywords: Balloon, Cyanosis, Foreign body aspiration, Respiratory distress

\section{Introduction}

Foreign body aspiration with subsequent airway obstruction typically occurs in children between the ages of six months and five years. Foreign body aspiration may be an ominous emergency in an infant. Commonly encountered foreign bodies are hazelnuts, pistachio nuts, candies, beans, popcorn, grapes, dried grapes, carrots, sausages and plant seeds. Pen caps, coins, balloons, marbles, little particles of various toys and pins are the usual aspirated foreign material. ${ }^{[1-3]}$ Balloon aspirations are killers for children. They are the number one cause of non-food related choking deaths in children. ${ }^{[4]}$ We present here a fatal case of balloon aspiration in a nine month old child.

\section{Case Report}

A 9 month old child is brought to the emergency ward with history of respiratory distress and gasping breathing since few minutes after swallowing an object unknown to the parents. On examination, the child was critically ill with feeble pulse, hypotension, gasping breathing and cyanosis. The child was intubated after checking the oral cavity for any object. During the resuscitation measures, the child did not improve. Pulse oximetry continued to be low despite all efforts. Chest $\mathrm{X}$-ray done during the period did not show pneumothorax or any radio opaque foreign body. Blood gases revealed severe hypoxia with severe metabolic acidosis. Child was being planned to be taken up for emergency tracheostomy, and rigid bronchoscopic removal of foreign body, but child succumbed

\begin{tabular}{|l|l|}
\hline \multicolumn{2}{|c|}{ Access this article online } \\
\hline Quick Response Code: & \\
\hline & Website: www.amhsr.org \\
\hline & \\
\hline
\end{tabular}

during resuscitation measures. During the removal of the endotracheal tube the balloon came along with it, which revealed the source of the aspirated foreign body.

\section{Discussion}

The diagnosis of foreign body aspiration requires a high index of suspicion because the diagnosis is often not obvious. Ninety percent of deaths from foreign body aspiration occur in patients who are younger than 5 years, and two thirds of these deaths occur in infants. Aspiration of food particles is more frequently encountered less than in the first year of age, whereas foreign bodies other than food material are more common in older children. ${ }^{[5]}$

Bronchoscopic removal is the recommended treatment as it is safe and effective. ${ }^{[6]}$

Children, especially those aged 1-3 years, are at risk for foreign body aspiration because of their tendency to put everything in their mouths. Young children chew their food incompletely with incisors due to the absence of molars. In addition, the toddlers sucking or inflating balloons are under the risk of suffocation. ${ }^{[1,2]}$ Objects or fragments may be propelled posteriorly, triggering a reflex inhalation.

In children with airway foreign bodies, chest radiograph findings are frequently normal and can display abnormalities uncharacteristic for foreign body aspiration. ${ }^{[6]}$ Impacted subglottic foreign bodies may produce upper airway obstruction and clinical signs simulating croup or asthma, stridor. Soft tissue upper airway X-rays demonstrate sub-glottic narrowing of the upper airway with a homogenous poorly defined radio density within the narrow segment. Treating a balloon aspiration can be very difficult. The usual treatment for choking, the Heimlich maneuver, may be ineffective. Parents may try to remove the foreign body 
themselves, probably leading to a possible delay in instituting correct management. Trying to remove the balloon by cleaning the back of the child's throat with the finger may prove dangerous as it only push the balloon down farther and lead to more problems.

Most of the cases occur in low socio-economic background and uneducated and ignorant parents, educating the parents can be a major step in preventing the foreign body aspiration. There should be stricter guidelines for toy manufacturers as well as prominent product safety labeling that will inform consumers of the dangers of choking through age appropriate labeling of toys and high-risk items which can be aspirated. ${ }^{[7]}$

\section{References}

1. Abdel-Rahman HA. Fatal suffocation by rubber balloons in children: Mechanism and prevention. Forensic Sci Int 2000;108: 97-105.
2. Tan HKK, Brown K, McGili T, Kenna MA, Lund PL, Healy GB. Airway foreign bodies: A 10-year review. Int J Pediatr Otorhinolaryngol 2000;56:91-9.

3. Fitzpatrick PC, Guarisco JL. Pediatric airway foreign bodies. J La State Med Soc 1998;150:138-41.

4. Ryan CA, Yacoub W, Paton T, Avard D. Childhood deaths from toy balloons. Am J Dis Child 1990;144:1221-4.

5. Lifschultz BD, Donoghue ER. Deaths due to foreign body aspiration in children: The continuing hazard toy balloons. J Forensic Sci 1996;41: 247-51.

6. Zerella JT, Dimler M, McGill LC, Pippus KJ. Foreign body aspiration in children: Value of radiography and complications of bronchoscopy. J Pediatr Surg 1998; 33:1651-4.

7. Centers for Disease Control and Prevention. Non fatal choking-related episodes among children - United States, 2001. MMWR Morb Mortal Wkly Rep 2002;51:945-8.

How to cite this article: Dias E. An unusual case of foreign body aspiration in an infant. Ann Med Health Sci Res 2012;2:209-10.

Source of Support: Nil. Conflict of Interest: None declared.

Author Institution Mapping (AIM)

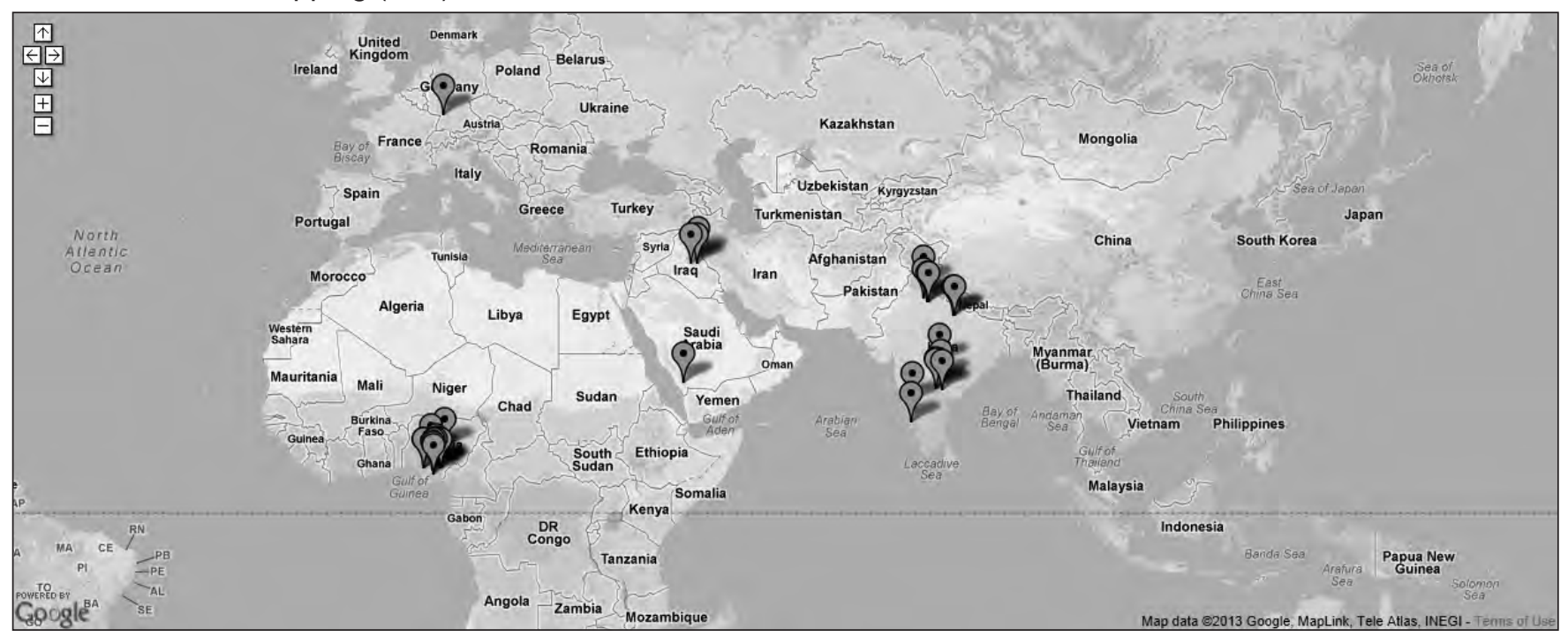

Please note that not all the institutions may get mapped due to non-availability of the requisite information in the Google Map. For AIM of other issues, please check the Archives/Back Issues page on the journal's website. 